\title{
Does disability increase households' health financial risk: evidence from the Uganda demographic and health survey
}

Wilfried Guets ${ }^{1 *}$ (D) and Deepak Kumar Behera ${ }^{2}$

\begin{abstract}
Background: In the last few years, there has been a worldwide commitment to protect the vulnerable individuals from higher financial risk through out-of-pocket (OOP) health expenditure. This study examines the influence of disability and socio-demographic factors on households' health financial risks in Uganda.

Methods: We used nationally representative cross-sectional data from the Uganda Demographic and Health Survey (UDHS) collected in 2016 by the Uganda Bureau of Statistics (UBOS) in Uganda. We measured financial risk (households' health expenditure) by money paid for health care services. We estimated the "probit" model to investigate the effect of disability on health financial risk.

Results: A total of 19,305 households were included in this study. Almost 32\% of households paid money for health care services access, among which $32 \%$ paid through out-of-pocket. Almost $41 \%$ of household heads were affected by disability. The majority (73\%) of families went to the public sector for health care services. The mean age was 45 years $(S D \pm 15)$. We find that disability is significantly associated with the household financial risk $(p<0.01)$. The private sector's choice for health care services is likely to positively affect the financial risk compared to the public sector $(p<0.01)$. The wealthier the household was, the more money paid for health service was $(p<0.01)$.
\end{abstract}

Conclusion: Our results indicated that disability and household socio-demographic characteristics were associated with health financial risk in Uganda. Identifying families with disability and experiencing difficult living conditions constitute an entry point for health authorities to enhance health coverage progress in low and middle-income countries.

Keywords: Disability, Health financial risk, Healthcare Payment, Socio-Demographic, Household Survey, Uganda JEL Classification: J14, 114, J1, 132, J71, C83

\section{Introduction}

In the last few years, there was a worldwide commitment to monitor and progress toward Universal Health Coverage (UHC in the last few years). The United Nation's Sustainable Development Goals (SDGs) has aimed to provide universal access to healthcare for all under the

*Correspondence: guets@gate.cnrs.fr

1 Univ Lyon, Université Lumière Lyon 2, GATE UMR 5824, 69130 Ecully, France

Full list of author information is available at the end of the article health-related SDGs-3 by 2030. One of the goals is to provide financial risk protection to all vulnerable irrespective of age, gender, caste, and religion. Nevertheless, people with disabilities remain the most vulnerable group in society, but people with disabilities are not explicitly mentioned in SDG-3 to ensure healthy lives for all [1]. Few have argued that without considering people with disabilities who have more significant health needs, the achievement of universal health care may not be genuinely inclusive [2-4]. original author(s) and the source, provide a link to the Creative Commons licence, and indicate if changes were made. The images or other third party material in this article are included in the article's Creative Commons licence, unless indicated otherwise in a credit line to the material. If material is not included in the article's Creative Commons licence and your intended use is not permitted by statutory regulation or exceeds the permitted use, you will need to obtain permission directly from the copyright holder. To view a copy of this licence, visit http://creativecommons.org/licenses/by/4.0/. 
Regarding the commitment of developing countries across the globe, Uganda has not escaped this significant shift. The search for collective well-being has become a significant challenge for low-income groups, vulnerable, fragile, and disabled people. On the 25th of September 2008, Uganda's government ratified both the convention and protocol of the United Nations Convention on the Rights of Persons with Disabilities (CRPD $)^{1}$ [5]. Then, various plans were implemented to protect, enhance the rights, and include people with disabilities. ${ }^{2}$ For instance, the National Planning Authority's (NPA) Second National Development Plan 2015/16-2019/20 (NDPII) [6, 7].

The design and implementation of government strategy for disability and inclusion in Uganda have shed light on gaps in policies and plans. Various research, such as [8], analyse the progress of disabilities policies and programs in Uganda since the last decade and explores a few critical challenges ahead. They have found that Uganda has excelled in advocating disabilities related comprehensive policies and their legal rights for healthcare services among sub-Saharan African countries. However, there seems to be an implementation gap between laws, policies, and programs. The implementation gap arises due to inadequate funding and lack of awareness leading to the exclusion of disabled people from getting any financial risk protection benefits. According to the disability statistics from the Uganda Demographic and Health Survey, on the one hand, $26 \%$ of the household population age five and above-faced difficulty at least any types of disabilities (seeing, hearing, communicating, remembering, walking, and washing) [9]. These statistics may vary according to the socio-economic and demographic characteristics of households.

On the other hand, there is less health insurance coverage (i.e. 6\%) for any healthcare payment services that might constitute a significant part of out-of-pocket health expenditure and increase the financial risk burden among the vulnerable households in Uganda. Based on the latest data from [9], around $94 \%$ of men and women members of families do not have health insurance, and the percentage of women and men with insurance increased slightly from 1 to 2\%, respectively, in 2011 to $6 \%$ each in 2016 . This study aims to analyse the influence of disability and socio-economics and demographic characteristics on households' healthcare services payment risk in Uganda

\footnotetext{
${ }^{1}$ The Uganda Persons with Disability Act 2006 considered disability as a "substantial functional limitation of daily life activities caused by physical, mental or sensory impairment and environmental barriers resulting in limited participation.."

2 The National Planning Authority's (NPA) Second National Development Plan 2015/16-2019/20 (NDPII) and the MoGLSD's Social Development Sector Plan 2015/16-2019/20 (SDSP) illustrate this.
}

on this above backdrop. This research includes cross-sectional and nationwide survey data in Uganda.

\section{Methods \\ Research design}

In this paper, we performed a quantitative analysis using cross-sectional survey data to investigate the effects of disability on households' health financial risk by controlling socio-economics characteristics of households heads living with disabilities in Uganda.

\section{Variables}

We have adopted households' financial risk payment as the dependent variable in this study. Household's health financial risk was measured by money paid to access health care services. Households' heads were asked to answer the question: "Do you pay any money for the services offered?" Payment for health care includes (1) directly out-of-pocket; (2) community-based initiative/ saving; (3) health insurance through employer; (4) other privately purchased commercial health insurance. ${ }^{3}$

The UDHS (2016) also included the DHS program disability section, a list of questions based on the Washington Group on Disability Statistics (WG) short Set referring to the International Classification of Functioning, Disability and Health (ICF) adopted by the World Health Organisation (WHO). ${ }^{4}$ The disability was measured following the six different functional domains: seeing, hearing, communicating, remembering or concentrating, walking or climbing steps, and washing all over or dressing (selfcare).$^{5}$ We recorded the disability variable as " 1 " if the respondent reported any of those.

Then, we considered determinants such as marital status, residence (rural), region, the choice of the private sector for health care, education, wealth (index), age, gender, number of children under five.

Further details regarding socio-economic and demographic characteristics are available on the Uganda DHS project. $^{6}$

\footnotetext{
${ }^{3}$ It is important to note the number of families having access to health insurance through employer; social security; and other privately purchased commercial health insurance were quite low in Uganda.

${ }^{4}$ https://www.who.int/standards/classifications/international-classifica tion-of-functioning-disability-and-health/who-disability-assessment-sched ule.

${ }^{5}$ This approach provides basic essential information on disability comparable to those collected worldwide via Washington Group (WG) disability tools. Based on the household questionnaire, respondents were aged 15 or above.

${ }^{6}$ https://dhsprogram.com/data/dataset/Uganda_Standard-DHS_2016.cfm? flag $=0$.
} 


\section{Data sources}

The Uganda Demographic and Health Survey (UDHS) was a cross-sectional, nationally representative data conducted in 2016 by the Uganda Bureau of Statistics (UBOS) between June and December 2016 [9]. The UDHS project aimed to provide recent evidence on basic demographic and health indicators (key demographic indicators such as fertility, under-five, and adult mortality; contraceptive knowledge and practice; malaria prevalence; child feeding practices; a key aspect of child and maternal health; key education indicators; extend of gender-based violence and disability. ${ }^{7}$ We used data based on the survey questionnaire (household), where demographic information and person characteristics were collected (age, sex, marital status, education, relationship with the household head). The UDHS also collected information on the money paid by households for health care services. In particular, the respondent provided information on the different ways they mobilised to finance health care access, out-of-pocket, community-based initiative/saving, health insurance through an employer, and other privately purchased commercial health insurance. The survey was conducted on 19,588 households. Interviews were done face-to-face across the 15 regions of the country. Further information is available on the survey website. ${ }^{8}$

\section{Data processing and analysis}

Descriptive statistics were used to provide more insight into the study sample. Then, we estimated the simple and multivariate "probit" models to investigate characteristics and factors associated with health financial risk. We estimated the following multivariate econometric equation:

$$
\text { Financialrisk }_{i}=\beta_{0}+\beta_{1} \text { Disability }_{i}+\beta_{2} X_{i}+\varepsilon_{i}
$$

where Financialrisk ${ }_{i}$ represents the dependent variable to explain. Disability $i$ is a binary variable and define as "Yes" if the household's head reported any form of functional limitation and "No" elsewhere. $X_{i}$ represents other explanatory variables. $\beta_{i}$ stands or the parameter to estimate. $\varepsilon_{i}$ is the error term.

We used the STATA SE 64 statistical software 14.2 (StataCorp, LP, College Station, TX, USA) for statistical and econometric analysis.

\footnotetext{
${ }^{7}$ https://dhsprogram.com/pubs/pdf/FR333/FR333.pdf.

8 https://dhsprogram.com/data/dataset/Uganda_Standard-DHS_2016.cfm? flag $=0$.
}

Table 1 Descriptive statistics of socio-economic and demographic characteristics

\begin{tabular}{|c|c|c|}
\hline Variables & $\mathrm{N}=19,305(\%)$ & $p$ value \\
\hline \multicolumn{3}{|l|}{ Wealth index (\%) } \\
\hline Q1 & $4874(25)$ & 0.00 \\
\hline Q2 & $4848(25)$ & \\
\hline Q3 & $4831(25)$ & \\
\hline Q4 & $4752(25)$ & \\
\hline \multicolumn{3}{|l|}{ Marital status (\%) } \\
\hline Single & $1257(6)$ & 0.00 \\
\hline Married & $13,535(70)$ & \\
\hline Widowed, Divorced or Separated & $4513(24)$ & \\
\hline \multicolumn{3}{|l|}{ Education (\%) } \\
\hline No education & $3179(16)$ & 0.00 \\
\hline Primary & $10,172(53)$ & \\
\hline More than secondary & $5954(31)$ & \\
\hline \multicolumn{3}{|l|}{ Residence area (\%) } \\
\hline Urban & $4353(23)$ & 0.00 \\
\hline Rural & $14,952(77)$ & \\
\hline \multicolumn{3}{|l|}{ Gender (\%) } \\
\hline Male & $13,273(69)$ & 0.00 \\
\hline Female & $6032(31)$ & \\
\hline \multicolumn{3}{|l|}{ Region (\%) } \\
\hline Central & $4547(24)$ & 0.00 \\
\hline Eastern & $3934(20)$ & \\
\hline Northern & $5722(30)$ & \\
\hline Western & $5102(26)$ & \\
\hline Disability (\%) & $7979(41)$ & \\
\hline Pay for health care service (\%) & $6218(32)$ & 0.00 \\
\hline Out of pocket (\%) & $6123(32)$ & 0.00 \\
\hline Community-based initiative or savings (\%) & $26(0.13)$ & 0.92 \\
\hline Health insurance through employer (\%) & $95(0.49)$ & 0.00 \\
\hline Social security (\%) & $2(0.01)$ & 0.23 \\
\hline Private insurance (\%) & $14(0.09)$ & 0.10 \\
\hline \multicolumn{3}{|l|}{ The sector used for health care services (\%) } \\
\hline Public sector & $14,081(72.94)$ & 0.00 \\
\hline Private sector & $5224(27.06)$ & \\
\hline Age $( \pm S D)$, mean & $42(15)$ & $0.00^{\mathrm{a}}$ \\
\hline Number of children under $5( \pm S D)$, mean & $0.97(1.02)$ & $0.00^{\mathrm{a}}$ \\
\hline
\end{tabular}

" $p$ value" represents the test of "Chi-Squared" (Chi2) with the variable "disability"

a This result represents the " $p$ value" of the Student test with the variable "disability". The $p$ value stands for the bivariate statistical "Chi-Squared" test for the categorical variables and the "Student" test for continuous variables. A $p$ value $<5 \%$ indicated the existence of a significant relationship between the two variables tested

\section{Results}

Descriptive statistics

The study sample included 19,305 households in Uganda and was collected from the Uganda Demographic 
and Health Survey (DHS, ${ }^{9}$ 2016). Table 1 presents the descriptive statistics of the sample households' socioeconomic and demographic characteristics in Uganda.

As indicated in Table 1, of the 19,305 households (with complete cases), almost $41 \%$ of household heads were affected by disability. Only $6 \%$ of household heads were single, $70 \%$ were married, and $23 \%$ were widowed, divorced, or separated. Almost 16\% of household heads were not educated, $53 \%$ had a primary education level, and $31 \%$ more than secondary education. The majority of households were living in rural areas (77\%). The majority of the heads of households were men (69\%). Nearly $24 \%$ of households were in the central region, $20 \%$ in the Eastern region, $30 \%$ in the Northern region, and $26 \%$ in the Western region. Almost 33\% of households paid money for health care services access, among which $32 \%$ paid through out-of-pocket, $0.13 \%$ through community-based initiative or savings, $0.5 \%$ by health insurance through an employer. The majority (73\%) of households went to the public sector for health care services. The mean age was 42 years $(S D \pm 15)$. The mean of number of children under 5 years old was one per household.

\section{Empirical results \\ Main results}

Table 2 shows the empirical results analysing factors associated with health financial risk. The multivariate econometric model (model 2) indicated that most explanatory variables were associated with health financial risk. We find that disability is significantly associated with the household financial risk $(p<0.01)$. Our results also show that the private sector choice for health care services is likely to be associated with the financial risk compared to the public sector $(p<0.01)$. Our model indicated that the wealthier the household was, the more money paid for health services was $(p<0.01)$. Married households' heads were more likely to spend more money on health than a single $(p<0.1)$. Paying for health care services were likely to reduce with ageing $(p<0.01)$. We also find a nonlinear relationship (U-shape form) between age and the financial risk in health. After 45 years $[0.018 /(2 * 0.0002)]$, we noticed that age was likely to induce a health financial risk. The regions were significantly and negatively associated with financial risk. Nevertheless, the residence area (rural), gender (female), number of children underfive were not associated with the financial risk on health. Interactions analyses indicated that the financial risk is significantly reduced with disability and for households

\footnotetext{
${ }^{9}$ The 2016 Uganda Demographic and Health Survey (2016 DHS) was implemented by Uganda Bureau of Statistics, Government of Uganda. This survey provides information on population health and nutrition programme in every 5 years.
}

living in the northern and western regions of the country compared to the central area.

\section{Robustness checks}

Further, we assumed the different components/forms of household health spending on health. We considered five types of payment sources for health care services as dependent variables: out-of-pocket spending, community-based initiative or saving, health insurance through an employer, and private insurance and examined socioeconomic and demographic characteristics.

Table 3 indicated that disability significantly influenced the out-of-pocket spending $(p<0.01)$ while it likely reduces private insurance spending $(p<0.05)$. The choice for the private sector for health care significantly affected the health expenditure; this effect was significant for out-of-pocket $(p<0.01)$, community-based initiative or savings $(p<0.01)$, health insurance through an employer $(p<0.01)$, and private insurance $(p<0.01)$. Households in the highest wealth quintile were more likely to spend more money on health services $(p<0.01)$. Being married have a positive influence on out-of-pocket spending $(p<0.05)$. The age was negatively associated with out-of-pocket $(p<0.01)$. Conversely, age is significantly associated with health insurance spending through an employer $(p<0.1)$. For health care access, families in the Western region of the country, in particular, were more likely to pay less in terms of out-of-pocket $(p<0.01)$ but contribute more in terms of community-based initiative or savings $(p<0.01)$.

\section{Discussion}

This study reports finding based on nationally representative data from the Uganda Demographic and Health Survey (UDHS) on the various healthcare services payments utilisation by households associated with disability. To reduce financial risk due to healthcare services, these vulnerable groups should be prioritised to achieve UHC $[1,10]$. However, limited research has been conducted to investigate the impact of disability and other socio-demographic factors on households' financial risk due to healthcare payment services in sub-Saharan African countries as Uganda, where $26 \%$ of the households fall into disabilities $[8,11,12]$. The majority of studies analysed the burden of chronic illness and multimorbidity on out-of-pocket health expenditure and measured catastrophic [3, 13, 14]. Very few tried to link disability and poverty relationships by measuring impoverishment in the same vein $[2,15]$. Therefore, we examined the impact of disabilities and socio-demographic characteristics on the households' financial risk on healthcare payment across payment sources: out-of-pocket spending, 
Table 2 Probit model_Factors associated with the payment of health care services (per component)

\begin{tabular}{|c|c|c|c|c|}
\hline & \multirow{2}{*}{$\begin{array}{l}\text { Model } 1 \\
\text { Pay for health care } \\
\text { service }\end{array}$} & \multicolumn{2}{|l|}{ Model 2} & \multirow{2}{*}{$\begin{array}{l}\text { Model } 2 \text { bis } \\
\text { Pay for health } \\
\text { care service with } \\
\text { interactions }\end{array}$} \\
\hline & & $\begin{array}{l}\text { Pay for health care } \\
\text { service }\end{array}$ & $\begin{array}{l}\text { Marginal effects } \\
\text { (M.E.) }\end{array}$ & \\
\hline Disability & $\begin{array}{l}-0.218^{* * *} \\
(0.019)\end{array}$ & $\begin{array}{l}0.076^{*} \\
(0.032)\end{array}$ & 0.01 & $\begin{array}{l}0.401^{* * *} \\
(0.112)\end{array}$ \\
\hline Private sector for health care & $\begin{array}{l}3.229^{* * *} \\
(0.037)\end{array}$ & $\begin{array}{l}3.136^{* * *} \\
(0.038)\end{array}$ & 0.40 & $\begin{array}{l}3.140^{* * *} \\
(0.038)\end{array}$ \\
\hline Wealth-Q1 & Ref & Ref & & Ref \\
\hline Q2 & $\begin{array}{l}0.257^{* * *} \\
(0.029)\end{array}$ & $\begin{array}{l}0.065 \\
(0.042)\end{array}$ & & $\begin{array}{l}0.063 \\
(0.042)\end{array}$ \\
\hline Q3 & $\begin{array}{l}0.437^{* * *} \\
(0.028)\end{array}$ & $\begin{array}{l}0.123^{* *} \\
(0.045)\end{array}$ & 0.02 & $\begin{array}{l}0.120^{* *} \\
(0.045)\end{array}$ \\
\hline Q3 & $\begin{array}{l}1.146^{* * *} \\
(0.028)\end{array}$ & $\begin{array}{l}0.341^{* * *} \\
(0.055)\end{array}$ & 0.05 & $\begin{array}{l}0.340^{* * *} \\
(0.055)\end{array}$ \\
\hline Marital status-(Single) & Ref & Ref & & Ref \\
\hline Married & $\begin{array}{l}-0.645^{* * *} \\
(0.037)\end{array}$ & $\begin{array}{l}0.165^{*} \\
(0.074)\end{array}$ & 0.02 & $\begin{array}{l}0.158^{*} \\
(0.073)\end{array}$ \\
\hline Widowed, Divorced or Separated & $\begin{array}{l}-0.730^{* * *} \\
(0.041)\end{array}$ & $\begin{array}{l}0.100 \\
(0.081)\end{array}$ & & $\begin{array}{l}0.094 \\
(0.080)\end{array}$ \\
\hline Education-(No education) & Ref & Ref & & Ref \\
\hline Primary & $\begin{array}{l}0.254^{* * *} \\
(0.028)\end{array}$ & $\begin{array}{l}-0.026 \\
(0.042)\end{array}$ & & $\begin{array}{l}-0.030 \\
(0.042)\end{array}$ \\
\hline More than secondary & $\begin{array}{l}0.706^{* * *} \\
(0.030)\end{array}$ & $\begin{array}{l}-0.046 \\
(0.051)\end{array}$ & & $\begin{array}{l}-0.047 \\
(0.051)\end{array}$ \\
\hline Rural & $\begin{array}{l}-0.601^{* * *} \\
(0.022)\end{array}$ & $\begin{array}{l}0.027 \\
(0.043)\end{array}$ & & $\begin{array}{l}0.022 \\
(0.043)\end{array}$ \\
\hline Female & $\begin{array}{l}-0.101^{* * *} \\
(0.020)\end{array}$ & $\begin{array}{l}-0.070 \\
(0.038)\end{array}$ & & $\begin{array}{l}-0.068 \\
(0.038)\end{array}$ \\
\hline Age & $\begin{array}{l}-0.008^{* * *} \\
(0.001)\end{array}$ & $\begin{array}{l}-0.018^{* * *} \\
(0.005)\end{array}$ & 0.002 & $\begin{array}{l}-0.020^{* * *} \\
(0.005)\end{array}$ \\
\hline Age squared & $\begin{array}{l}0.000^{* * *} \\
(0.000)\end{array}$ & $\begin{array}{l}0.000^{* *} \\
(0.000)\end{array}$ & & $\begin{array}{l}0.000^{* * *} \\
(0.000)\end{array}$ \\
\hline Region-(Central) & Ref & Ref & & Ref \\
\hline Eastern & $\begin{array}{l}-0.700^{* * *} \\
(0.028)\end{array}$ & $\begin{array}{l}-0.117^{* *} \\
(0.045)\end{array}$ & 0.02 & $\begin{array}{l}-0.106 \\
(0.059)\end{array}$ \\
\hline Northern & $\begin{array}{l}-1.048^{* * *} \\
(0.027)\end{array}$ & $\begin{array}{l}-0.266^{* * *} \\
(0.047)\end{array}$ & 0.04 & $\begin{array}{l}-0.195^{* * *} \\
(0.058)\end{array}$ \\
\hline Western & $\begin{array}{l}-0.738^{* * *} \\
(0.026)\end{array}$ & $\begin{array}{l}-0.327^{* * *} \\
(0.042)\end{array}$ & 0.04 & $\begin{array}{l}-0.243^{* * *} \\
(0.055)\end{array}$ \\
\hline Number of children under 5 & $\begin{array}{l}-0.099^{* * *} \\
(0.009)\end{array}$ & $\begin{array}{l}0.004 \\
(0.014)\end{array}$ & & $\begin{array}{l}0.004 \\
(0.014)\end{array}$ \\
\hline Disability* Age & & & & $\begin{array}{l}-0.005^{*} \\
(0.002)\end{array}$ \\
\hline Disability*Eastern & & & & $\begin{array}{l}-0.043 \\
(0.088)\end{array}$ \\
\hline Disability* Northern & & & & $\begin{array}{l}-0.183^{*} \\
(0.082)\end{array}$ \\
\hline Disability*Western & & & & $\begin{array}{l}-0.200^{*} \\
(0.082)\end{array}$ \\
\hline Constant & $\begin{array}{l}-0.374^{* * *} \\
(0.012)\end{array}$ & $\begin{array}{l}-1.030^{* * *} \\
(0.128)\end{array}$ & & $\begin{array}{l}-1.054^{* * *} \\
(0.130)\end{array}$ \\
\hline Number of observations & 19,305 & 19,305 & 19,305 & 19,305 \\
\hline
\end{tabular}

Standard errors in parentheses. Model 1 stands for univariates, whereas model 2 represents the multivariate model. M.E. represents marginal effects for the model 2 ${ }^{*} p<0.05 ;{ }^{* *} p<0.01 ;{ }^{* * *} p<0.001$ 
Table 3 Probit model_Factors associated with the payment of health care services across source healthcare spending

\begin{tabular}{|c|c|c|c|c|}
\hline & $\begin{array}{l}\text { (1) } \\
\text { Out of pocket }\end{array}$ & $\begin{array}{l}\text { (2) } \\
\text { Community-based } \\
\text { initiative or savings }\end{array}$ & $\begin{array}{l}\text { (3) } \\
\text { Health insurance through } \\
\text { an employer }\end{array}$ & $\begin{array}{l}\text { (4) } \\
\text { Private insurance }\end{array}$ \\
\hline Disability & $\begin{array}{l}0.092^{* *} \\
(0.031)\end{array}$ & $\begin{array}{l}0.039 \\
(0.150)\end{array}$ & $\begin{array}{l}-0.248 \\
(0.128)\end{array}$ & $\begin{array}{l}-0.423^{* *} \\
(0.154)\end{array}$ \\
\hline Private sector for health care & $\begin{array}{l}2.970^{* * *} \\
(0.034)\end{array}$ & $\begin{array}{l}0.959^{* * *} \\
(0.166)\end{array}$ & $\begin{array}{l}0.721^{* * *} \\
(0.115)\end{array}$ & $\begin{array}{l}1.038^{* * *} \\
(0.295)\end{array}$ \\
\hline Q1 & Ref & Ref & Ref & Ref \\
\hline Q2 & $\begin{array}{l}0.076 \\
(0.041)\end{array}$ & $\begin{array}{l}-0.147 \\
(0.287)\end{array}$ & $\begin{array}{l}-0.095 \\
(0.163)\end{array}$ & $\begin{array}{l}-0.274 \\
(0.244)\end{array}$ \\
\hline Q3 & $\begin{array}{l}0.151^{* * *} \\
(0.043)\end{array}$ & $\begin{array}{l}0.264 \\
(0.253)\end{array}$ & $\begin{array}{l}-0.344^{*} \\
(0.168)\end{array}$ & $\begin{array}{l}0.000^{\mathrm{a}} \\
-\end{array}$ \\
\hline Q3 & $\begin{array}{l}0.311^{* * *} \\
(0.054)\end{array}$ & $\begin{array}{l}0.075 \\
(0.271)\end{array}$ & $\begin{array}{l}0.000^{\mathrm{a}} \\
-\end{array}$ & $\begin{array}{l}0.000^{\mathrm{a}} \\
-\end{array}$ \\
\hline Single & Ref & Ref & Ref & Ref \\
\hline Married & $\begin{array}{l}0.216^{* *} \\
(0.071)\end{array}$ & $\begin{array}{l}-0.234 \\
(0.275)\end{array}$ & $\begin{array}{l}-0.080 \\
(0.146)\end{array}$ & $\begin{array}{l}-0.339 \\
(0.270)\end{array}$ \\
\hline Widowed, divorced or separated & $\begin{array}{l}0.176^{*} \\
(0.077)\end{array}$ & $\begin{array}{l}-0.362 \\
(0.284)\end{array}$ & $\begin{array}{l}-0.341 \\
(0.183)\end{array}$ & $\begin{array}{l}-0.646^{*} \\
(0.311)\end{array}$ \\
\hline No education & Ref & Ref & Ref & Ref \\
\hline Primary & $\begin{array}{l}-0.019 \\
(0.041)\end{array}$ & $\begin{array}{l}0.134 \\
(0.256)\end{array}$ & $\begin{array}{l}-0.582^{* * *} \\
(0.133)\end{array}$ & $\begin{array}{l}0.198 \\
(0.374)\end{array}$ \\
\hline More than secondary & $\begin{array}{l}-0.090 \\
(0.050)\end{array}$ & $\begin{array}{l}0.230 \\
(0.292)\end{array}$ & $\begin{array}{l}0.000^{\mathrm{a}} \\
-\end{array}$ & $\begin{array}{l}0.369 \\
(0.327)\end{array}$ \\
\hline Rural & $\begin{array}{l}0.068 \\
(0.042)\end{array}$ & $\begin{array}{l}0.073 \\
(0.170)\end{array}$ & $\begin{array}{l}-0.406^{* * *} \\
(0.101)\end{array}$ & $\begin{array}{l}0.116 \\
(0.147)\end{array}$ \\
\hline Female & $\begin{array}{l}-0.073^{*} \\
(0.036)\end{array}$ & $\begin{array}{l}-0.074 \\
(0.188)\end{array}$ & $\begin{array}{l}0.088 \\
(0.103)\end{array}$ & $\begin{array}{l}0.478^{* *} \\
(0.161)\end{array}$ \\
\hline Age & $\begin{array}{l}-0.019^{* * *} \\
(0.005)\end{array}$ & $\begin{array}{l}0.008 \\
(0.027)\end{array}$ & $\begin{array}{l}0.050^{*} \\
(0.024)\end{array}$ & $\begin{array}{l}0.025 \\
(0.028)\end{array}$ \\
\hline Age squared & $\begin{array}{l}0.000^{* * *} \\
(0.000)\end{array}$ & $\begin{array}{l}-0.000 \\
(0.000)\end{array}$ & $\begin{array}{l}-0.001 \\
(0.000)\end{array}$ & $\begin{array}{l}-0.000 \\
(0.000)\end{array}$ \\
\hline Central & Ref & Ref & Ref & Ref \\
\hline Eastern & $\begin{array}{l}-0.076 \\
(0.044)\end{array}$ & $\begin{array}{l}0.000^{\mathrm{a}} \\
-\end{array}$ & $\begin{array}{l}-0.475^{*} \\
(0.195)\end{array}$ & $\begin{array}{l}0.000^{\mathrm{a}} \\
-\end{array}$ \\
\hline Northern & $\begin{array}{l}-0.224^{* * *} \\
(0.046)\end{array}$ & $\begin{array}{l}0.521 \\
(0.349)\end{array}$ & $\begin{array}{l}-0.163 \\
(0.156)\end{array}$ & $\begin{array}{l}0.000^{\mathrm{a}} \\
-\end{array}$ \\
\hline Western & $\begin{array}{l}-0.299^{* * *} \\
(0.041)\end{array}$ & $\begin{array}{l}1.206^{* * *} \\
(0.281)\end{array}$ & $\begin{array}{l}-0.113 \\
(0.127)\end{array}$ & $\begin{array}{l}0.290^{*} \\
(0.131)\end{array}$ \\
\hline Number of children under 5 & $\begin{array}{l}0.010 \\
(0.014)\end{array}$ & $\begin{array}{l}0.039 \\
(0.059)\end{array}$ & $\begin{array}{l}-0.194^{*} \\
(0.081)\end{array}$ & $\begin{array}{l}0.082 \\
(0.102)\end{array}$ \\
\hline Constant & $\begin{array}{l}-1.117^{* * *} \\
(0.124)\end{array}$ & $\begin{array}{l}-4.671^{* * *} \\
(0.563)\end{array}$ & $\begin{array}{l}-3.171^{* * *} \\
(0.468)\end{array}$ & $\begin{array}{l}-4.753^{* * *} \\
(0.592)\end{array}$ \\
\hline Number of observations & 19,305 & 15,371 & 12,729 & 5882 \\
\hline
\end{tabular}

Standard errors in parentheses. The different components are: (1) Directly out-of-pocket; (2) community-based initiative/saving; (3) health insurance through an employer; (4) other privately purchased commercial health insurance

${ }^{*} p<0.05 ;{ }^{* *} p<0.01 ;{ }^{* * *} p<0.001$

${ }^{\text {a }}$ Not estimated due to the weakness of sample and variable contains many missing values. Variables "Community-based initiative/saving", "health insurance through an employer", "other privately purchased commercial health insurance" contain missing data

community-based initiative or saving, health insurance through an employer, and private insurance.

In this study, we found that around $41 \%$ of household heads were affected by disability, and the majority of them have lived in rural areas, and men centric disabilities are more. Almost 32\% of households paid for healthcare services through their own out-of-pocket. A very negligible number of households were covered with health insurance (i.e. community-based or private health insurance). Our results concord with earlier studies finding that disability households usually face catastrophic medical expenses due to higher out-of-pocket payment 
services and low insurance payment coverage $[3,13,15]$. Specifically, wealthier households and married individuals are likely to spend more money on healthcare services than lower-income households and single-headed households. This relationship is evident because positive income elasticity of health spending might treat healthcare services as a normal good than the counterpart [16, 17]. We find no financial risk associated with those disability households residing in rural areas, female-headed households, and children under 5 years. This is a fascinating result and contrast view from the earlier literature. Some studies found that households living in a rural area and female participants were highly prone to financial risk due to higher out-of-pocket health payments $[14,18$, 19].

We have also found a close association between the choice of private healthcare payments and age categories. These findings shed light on the non-linear impact of age on out-of-pocket health spending. Younger age reduced out-of-pocket and opted for other payment sources such as employee health insurance. In comparison, in older age (i.e. age squared), health services' payment is derived from out-of-pocket. These results are similar to earlier finding that ageing is one of the pertinent factors for higher out-of-pocket payment, and it remains a debatable issue in health economics.

Conversely, few studies find that ageing has no longer a problem for households' catastrophic health payments in the Asia-pacific countries. They presumed that it might be a problem in the long run when these countries would move any demographic or epidemiological transition $[17,20]$. The results also highlighted a huge variation in the healthcare payment system across geographic regions of Uganda. For instance, the Western region has more access to community-based insurance and private insurance, which depends on the household's pocket expenditure.

The overall discussion concludes that out-of-pocket payment have a positive and significant effect on the financial risk of disabled households. A significantly less proportion of disabilities households reduce their financial risk through other payment modes-private insurance that only for higher wealth quintile households. Additionally, other socio-demographic factors impact household financial risk protection by using different healthcare payment services, including ageing, socioeconomic and development of regions in Uganda, and lower dependency households. Our results are following other studies investigating the association between disabilities and catastrophic health payment [3, 13, 21].

Given that, our study used nationwide data sets, there is no denying that it has several limitations. Our work relies on cross-sectional data, and therefore, morbidity due to disabilities and healthcare payment, and other variables or data were not easy to capture in this paper. Furthermore, our finding is based on self-reported healthcare payment and disabilities, which might cause a lag effect of the households' financial crisis or any recall bias related to healthcare payment. Some cautions should be taken regarding the dependent variable (private insurance) because many respondents did not/ refused to answer related questions.

\section{Conclusion}

This study examined the influence of disability and sociodemographic factors on households' health financial risks in Uganda. The findings show that disability and household socio-demographic characteristics were associated with health financial risk in Uganda. Identifying families with disabilities and experiencing difficult living conditions constitute an entry point for health authorities to enhance health coverage progress in low and middleincome countries. Despite a few limitations, our study fills a significant knowledge gap. It relied on cross-sectional and nationally representative data sets to estimate the effect of disability on households' healthcare services payments regarding different payment sources. These results have implications for health policies. One should design effective disability-health related policies in subSaharan African countries. Priorities should target fragile, vulnerable populations and groups with a high risk of financial impoverishment.

\section{Abbreviations \\ UBOS: Uganda bureau of statistics; UDHS: Uganda demographic and health survey; UHC: Universal health coverage; OOP: Out-of-pocket.}

\section{Acknowledgements}

The authors thank the Demographic and Health Surveys (DHS) Program project for the support and free access to the data. https://www.dhsprogram. $\mathrm{com} /$

\section{Authors' contributions}

WG conceptualised the idea. WG were responsible for the study design. WG conducted the data analysis. WG and DKB were responsible for drafting the manuscript. WG and DKB provided comments on successive drafts. All authors have read and approved the final manuscript.

\section{Funding}

The authors declare no funding.

\section{Availability of data and materials}

The datasets supporting this research's finding are available in the Demographic and Health Surveys (DHS) Program repository. https://dhsprogram. com/pubs/pdf/FR333/FR333.pdf; https://www.dhsprogram.com/

\section{Declarations}

Ethics approval and consent to participate Not applicable. 


\section{Consent for publication}

Not applicable.

\section{Competing interests}

The authors declare that they have no competing interests.

\section{Author details}

${ }^{1}$ Univ Lyon, Université Lumière Lyon 2, GATE UMR 5824, 69130 Ecully, France.

${ }^{2}$ Manipal Academy of Higher Education, Manipal 576104, India.

Received: 10 August 2021 Accepted: 26 December 2021

Published online: 05 January 2022

\section{References}

1. Hashemi G, Kuper H, Wickenden M. SDGs, inclusive health and the path to universal health coverage. Disabil Glob South. 2017:4:1088-111.

2. Banks LM, Kuper H, Polack S. Poverty and disability in low- and middleincome countries: a systematic review. PLoS ONE. 2017;12: e0189996. https://doi.org/10.1371/journal.pone.0189996.

3. Lee J-E, Shin H-I, Do YK, Yang EJ. Catastrophic health expenditures for households with disabled members: evidence from the Korean health panel. J Korean Med Sci. 2016;31:336-44.

4. Kuper H, Mactaggart I, Dionicio C, Cañas R, Naber J, Polack S. Can we achieve universal health coverage without a focus on disability? Results from a national case-control study in Guatemala. PLoS ONE. 2018;13: e0209774. https://doi.org/10.1371/journal.pone.0209774.

5. United Nations. United Nations Treaty Collection - 15. Convention on the Rights of Persons with Disabilities. United Nations 2006.

6. Government of Uganda. Second national development Plan (NDPII). 2014.

7. Ministry of Gender Labour and Social Development (MoGLSD). Sector Development Plans-National Planning Authority 2016. http://www.npa. go.ug/development-plans/sector-development-plans/. Accessed 14 Jan 2021.

8. Abimanyi-Ochom J, Mannan H. Uganda's disability journey: progress and challenges. African J Disabil. 2014. https://doi.org/10.4102/ajod.v3i1.108.

9. Uganda Bureau of Statistics - UBOS and ICF. Uganda Demographic and Health Survey 20162018.

10. Somkotra T, Lagrada LP. Which households are at risk of catastrophic health spending: Experience in Thailand after universal coverage. Health Aff. 2009. https://doi.org/10.1377/hlthaff.28.3.w467.

11. Wandera SO, Ntozi J, Kwagala B. Prevalence and correlates of disability among older Ugandans: Evidence from the Uganda national household survey. Glob Health Action. 2014. https://doi.org/10.3402/gha.v7.25686.

12. Pumkam C, Probst JC, Bennett KJ, Hardin J, Xirasagar S. Health care expenditures among working-age adults with physical disabilities: variations by disability spans. Disabil Health J. 2013;6:287-96. https://doi.org/ 10.1016/j.dhjo.2013.03.002.

13. Sultana M, Mahumud RA, Sarker AR. Burden of chronic illness and associated disabilities in Bangladesh: evidence from the household income and expenditure survey. Chronic Dis Transl Med. 2017;3:112-22. https://doi. org/10.1016/j.cdtm.2017.02.001.

14. Thavorn K, Maxwell CJ, Gruneir A, Bronskill SE, Bai Y, Koné Pefoyo AJ, et al. Effect of socio-demographic factors on the association between multimorbidity and healthcare costs: a population-based, retrospective cohort study. BMJ Open. 2017;7:17264. https://doi.org/10.1136/bmjop en-2017-017264.

15. Mitra S, Posarac A, Vick B. Disability and poverty in developing countries: a multidimensional study. World Dev. 2013;41:1-18. https://doi.org/10. 1016/j.worlddev.2012.05.024.

16. Behera DK, Dash U. Prioritization of government expenditure on health in India: a fiscal space perspective. Socioecon Plann Sci. 2019. https://doi. org/10.1016/j.seps.2018.11.004.

17. Behera DK, Dash U. Is health expenditure effective for achieving healthcare goals? Empirical evidence from South-East Asia Region. Asia-Pacific J Reg Sci. 2020;4:593-618. https://doi.org/10.1007/s41685-020-00158-4.

18. Li Y, Wu Q, Xu L, Legge D, Hao Y, Gao L, et al. Factors affecting catastrophic health expenditure and impoverishment from medical expenses in
China: policy implications of universal health insurance. Bull World Health Organ. 2012;90:664-71. https://doi.org/10.2471/BLT.12.102178.

19. del Pozo-Rubio R, Mínguez-Salido R, Pardo-García I, Escribano-Sotos F. Catastrophic long-term care expenditure: associated socio-demographic and economic factors. Eur J Heal Econ. 2019;20:691-701. https://doi.org/ 10.1007/s10198-019-01031-8.

20. Behera DK, Dash U. Healthcare financing in South-East Asia: Does fiscal capacity matter? Int J Healthc Manag. 2018. https://doi.org/10.1080/ 20479700.2018.1548159.

21. Mitra S, Findley PA, Sambamoorthi U. Health Care Expenditures of Living With a Disability: Total Expenditures, Out-of-Pocket Expenses, and Burden, 1996 to 2004. Arch Phys Med Rehabil. 2009;90:1532-40. https://doi.org/ 10.1016/j.apmr.2009.02.020.
Ready to submit your research? Choose BMC and benefit from:

- fast, convenient online submission

- thorough peer review by experienced researchers in your field

- rapid publication on acceptance

- support for research data, including large and complex data types

- gold Open Access which fosters wider collaboration and increased citations

- maximum visibility for your research: over $100 \mathrm{M}$ website views per year

At BMC, research is always in progress.

Learn more biomedcentral.com/submissions 